\title{
Effect of Temperature on I-V Characteristic for $\mathrm{ZnO} / \mathrm{CuO}$
}

\author{
Mubarak Dirar1, Farhah Elfadel Omer'1, Rawia Abdelgani1', Ali Sulaiman Mohamed2*, \\ Abdelnabi Ali Elamin², Bashir Elhaj Ahamed², Mona Ali'1, Abdelsakh Suleman Mohamed³
}

${ }^{1}$ Department of Physics, College of Science, Sudan University of Science and Technology, Khartoum, Sudan

${ }^{2}$ Department of Physics, Faculty of Science and Technology, Omdurman Islamic University, Omdurman, Sudan

${ }^{3}$ Department of Laser Physics, Faculty of Science, Meteorology Alneleen University, Khartoum, Sudan

Email: *aelamain@yahoo.com

How to cite this paper: Dirar, M., Omer, F.E., Abdelgani, R., Mohamed, A.S., Elamin, A.A., Ahamed, B.E., Ali, M. and Mohamed, A.S. (2018) Effect of Temperature on I-V Characteristic for $\mathrm{ZnO} / \mathrm{CuO}$. World Journal of Nuclear Science and Technology, 8, 128-135.

https://doi.org/10.4236/wjnst.2018.83011

Received: April 29, 2018

Accepted: July 10, 2018

Published: July 13, 2018

Copyright $\odot 2018$ by authors and Scientific Research Publishing Inc. This work is licensed under the Creative Commons Attribution International License (CC BY 4.0).

http://creativecommons.org/licenses/by/4.0/

c) (i) Open Access

\begin{abstract}
Research on nonmaterials has become increasingly popular because of their unique physical, chemical, optical and catalytic properties compared to their bulk counterparts. Therefore, many efforts have been made to synthesize multidimensional nanostructures for new and efficient nanodevices. Among those materials, zinc oxide $(\mathrm{ZnO})$ has gained substantial attention owing to many outstanding properties. $\mathrm{ZnO}$ besides its wide band gap of $3.34 \mathrm{eV}$ exhibits a relatively large excitons binding energy $(60 \mathrm{meV})$ at room temperature which is attractive for optoelectronic applications. Likewise, cupric oxide $(\mathrm{CuO})$ has a narrow band gap of $1.2 \mathrm{eV}$ and a variety of chemo-physical properties that are attractive in many fields. Moreover, composite nanostructures of these two oxides $(\mathrm{CuO} / \mathrm{ZnO})$ may pave the way for various new applications. So in this thesis, eight samples of $\mathrm{CuO} / \mathrm{ZnO}$ junction were synthesized and exposed to temperatures $60,70,80,90,100,110,120$ and 130 . The electrical properties of Schottky diode junctions were analyzed by I-V measurements under the influence of direct solar radiation and, lag of radiation (darkness) which shows the semi-logarithmic I-V characteristic curve of the fabricated photodiodes. Also energy band gap was estimated and the morphology and particle sizes of the as-prepared sample were determined by SEM. The SEM images of $\mathrm{ZnO}+$ $\mathrm{CuO}$ sample films were annealed at $60^{\circ} \mathrm{C}$ to $130^{\circ} \mathrm{C}$ step 10 .
\end{abstract}

\section{Keywords}

Copper Oxide, Zinc Oxide, Thin Films, Monoethanolamine, Temperature, Current-Voltage (I-V) Characteristic

\section{Introduction}

During the last few decades, nanomaterials have been the subject of extensive 
interest because of their potential use in a wide range of fields like, optoelectronics, catalysis and sensing applications. The physical and chemical properties of nanomaterials can differ significantly from their bulk counterpart because of their small size. In general, nanomaterials comprised novel properties that are typically not observed in their conventional, bulk counterparts. Nanomaterials have a much larger surface area to volume ratio than their bulk counterparts, which is one of the bases of their novel physical and/or chemical properties. Nanomaterials are classified into one-dimensional (1D), two-dimensional (2D) and three-dimensional (3D).

In addition, metal oxide nanomaterials have drawn a particular attention because of their excellent structural flexibility combined with other attractive properties. These metal oxides nanostructures not only inherit the fascinating properties from their bulk form such as piezoelectricity, chemical sensing, and photo detection, but also possess unique properties associated with their highly anisotropic geometry and size confinement [1]. The combinations of the new and the conventional properties with the unique effects of nanostructures make the investigation of novel metal oxide nanostructures a very important issue in research and development both from fundamental and industrial standpoints.

Among the various metal oxides, zinc oxide $(\mathrm{ZnO})$ possessed a considerable attention due to its unique properties and applications. In particular, $\mathrm{ZnO}$ nanostructures (NSs) are of intense interest since they can be grown by a variety of methods with different morphologies. Among the different growth methods, the chemical bath deposition method is low temperature, simple, inexpensive and environmentally friendly method. These are all factors which further contribute to the resurgent attention in $\mathrm{ZnO}$. Specifically, one-dimensional $\mathrm{ZnO}$ nanorods (NRs) amongst other nanostructures are attractive components for manufacturing nanoscale electronics and photonic devices as well as their biomedical applications because of their interesting chemical and physical properties [2] [3]. Also $\mathrm{ZnO}$ NRs can easily be grown on a variety of substrates like metal surface, semiconductors, glass, plastic and disposable paper substrates etc. [4] [5] [6] [7]. Furthermore, a direct wide band gap $\sim 3.37 \mathrm{eV}$ and relatively large excitonic binding energy $\sim 60 \mathrm{meV}$ of $\mathrm{ZnO}$ along with many radiative deep level defects, make $\mathrm{ZnO}$ attractive for its emission tendency in blue/ultraviolet and full colour lighting [8] [9]. To utilize theses properties of $\mathrm{ZnO}$ in LEDs application, another p-type material is necessary as $\mathrm{ZnO} \mathrm{NRs}$ is unintentionally $\mathrm{n}$-type material. Since mostly polymers are p-type and their special properties, like low cost, low power consumption, flexible and easy manufacturing, all make polymers a better choice to use with $\mathrm{ZnO}$ NRs to fabricate a flexible device that utilizes the properties of both materials for large area lighting and display application [10] [11].

On the other hand, natural abundance of copper (II) oxide $(\mathrm{CuO})$ as well as its low production cost, good electrochemical and catalytic properties makes the copper oxide to be one of the best materials for various applications. $\mathrm{CuO}$ also 
has a variety of nanostructures and can be grown using the low temperature aqueous chemical method. It is one of the most important catalysts and is widely used in environmental catalyst.

\section{Materials and Methods}

\subsection{Growth of CuO Thin Films}

Copper oxide $(\mathrm{CuO})$ thin films were prepared by dissolving 0.2 molar copper acetate and monoethanolamine in a 1:1 Molar ratio in $20 \mathrm{ml}$ of 2-methoxyethanol solvent. Acetic acid was added drop wise to achieve a homogeneous solution. The above stock solution was vigorously stirred at $80^{\circ} \mathrm{C}$ for $120 \mathrm{~min}$. The $\mathrm{Cu}$ aqueous solution was filtered through a $0.2 \mu \mathrm{m}$ poly-tetrafluoroethylene membrane and was aged for $24 \mathrm{~h}$. The colour of the solvent became dark green. The precursor solution was uniformly deposited on cleaned ITO glass substrates by spin coating technique at a spin speed of $2000 \mathrm{rpm}$ for $60 \mathrm{~s}$. The coating process was repeated to attain the desired thickness. The films were annealed at $90^{\circ} \mathrm{C}$ for 5 min after each layer deposition.

\subsection{Growth of ZnO Thin Films}

The precursor solution for fabricating zinc oxide thin films were prepared by dissolving 0.3 Molar zinc acetate and monoethanolamine (MEA) in a 1:1 Molar ratio in $20 \mathrm{ml}$ of 2-methoxyethanol solvent. MEA was added as a stabilizer to ameliorate the solubility of the precursors. Acetic acid is then added to achieve a homogeneous solution. Above mixture was stirred at $70^{\circ} \mathrm{C}$ for one hour. After stirring, the $\mathrm{Zn}$ aqueous solution was aged for $24 \mathrm{~h}$. The colour of the solvent then became yellowish orange. The precursor solution was uniformly deposited on ITO cleaned glass substrates that coating in it $\mathrm{CuO}$ by spin coating technique at a spin speed of $2000 \mathrm{rpm}$ for $60 \mathrm{~s}$. The coatings were repeated to achieve the desired thickness of $561.56 \mathrm{~nm}$. After each coating the films were baked at $70^{\circ} \mathrm{C}$ for $5 \mathrm{~min}$.

\subsection{Samples of $\mathrm{CuO}$ and ZnO Films Annealed at Various Temperatures}

The 8 samples of $\mathrm{CuO}$ and $\mathrm{ZnO}$ films were finally air annealed at various temperatures ranging from $(60,70,80,90,100,110,120 \text { and } 130)^{\circ} \mathrm{C}$ for three hours. Each layer was characterized by studying structural, electrical and optical properties. Glancing angle X-ray diffraction analysis of the films was performed with (XRD) system. Surface morphology of the film was studied by (SEM). Optical absorbance measurements were performed with UV-Vis spectrophotometer 1240 was performed at room-temperature. Electrical characterization of the resistive thin films and current voltage characteristics of $\mathrm{p}-\mathrm{n}$ junction were performed at room temperature using Kiethley 4200-SCS semiconductor parameter analyzer equipped with. 


\subsection{Characterization Studies}

\section{Scanning Electron Microscopy (SEM)}

The morphology and particle sizes of the as-prepared sample were determined by SEM ((SEM, Tuscan Vega LMU).. The SEM images of $\mathrm{ZnO}+\mathrm{CuO}$ sample films were annealed at $60^{\circ} \mathrm{C}$ temperatures are shown in Figure 1. These indicate that sphere-like $\mathrm{ZnO}+\mathrm{CuO}$ sample films were annealed at $60^{\circ} \mathrm{C}$ temperatures nanostructures obtained by this method are uniform in both morphology and particle size, but have agglomeration to some extent. The average size was calculated to be $1.5 \mu \mathrm{m}$ from the measurements on the SEM micrographs. Corresponding histograms, showing the particle size distribution, are also presented in Figure 2. The mean particle size $1.5 \mu \mathrm{m}$ estimated from SEM is in close agreement with the average crystallite size $1.514 \mu \mathrm{m}$ as calculated from histograms line broadening. The microstructure and chemical composition of the film surface were analyzed using a scanning electron microscope (SEM, Tuscan Vega $\mathrm{LMU})$. Their sizes are found to range from 1.5 to $1.514 \mu \mathrm{m}$.

\section{Results}

Table 1 clearly shows the lists of I-V reading for 8 samples for different temperature. The first column represents volts and the other columns show the current for different temperature.

Figure 3 shows the relationship between volts $\mathrm{ZnO} / \mathrm{CuO}$ p-n junction and current for 8 samples with annealed different temperatures from $60^{\circ} \mathrm{C}$ to $130^{\circ} \mathrm{C}$ in the darkness. From Figure 3, it clearly shows that upon increasing the temperature from 60 to 130 in steps of $10^{\circ} \mathrm{C}$, the current increases with temperature when the voltage is fixed. From Table 2 and Figure 4, it is clear that the current of
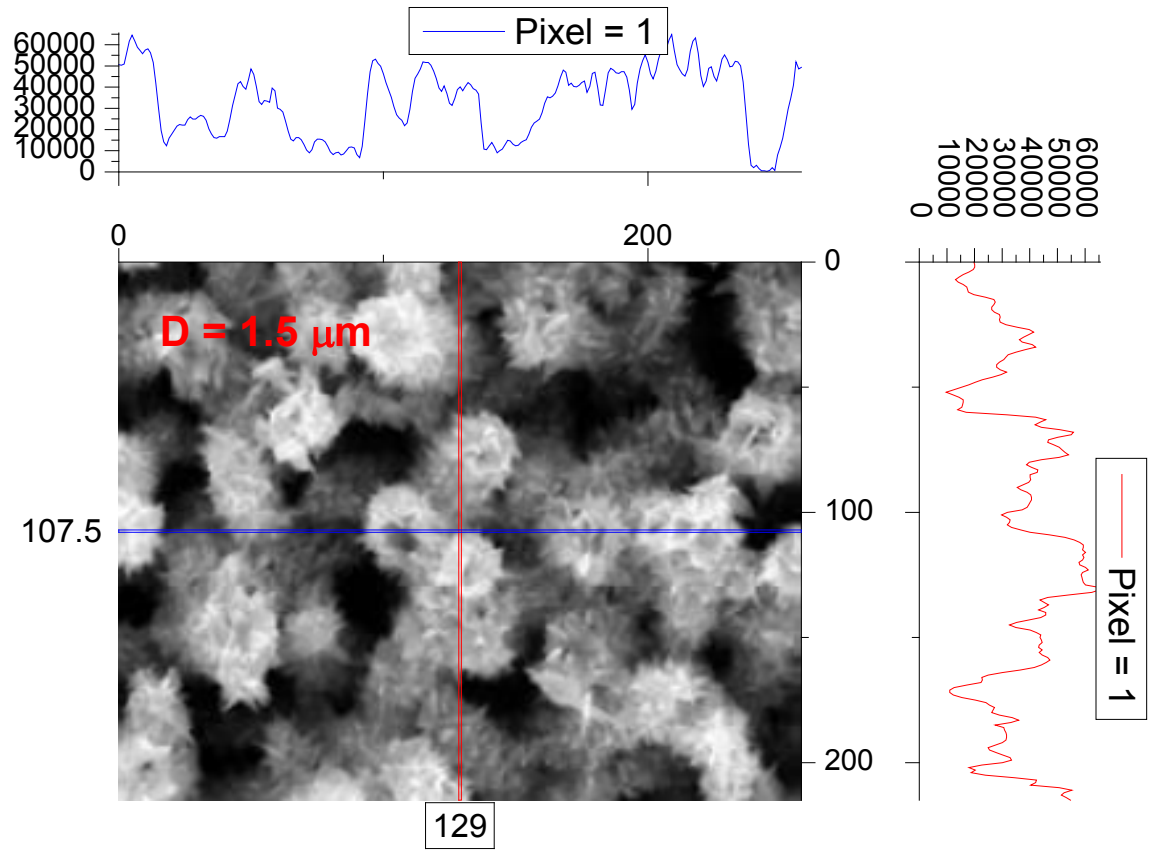

Figure 1. SEM images of the $\mathrm{ZnO}+\mathrm{CuO}$ sample films were annealed at $60^{\circ} \mathrm{C}$ temperatures. 


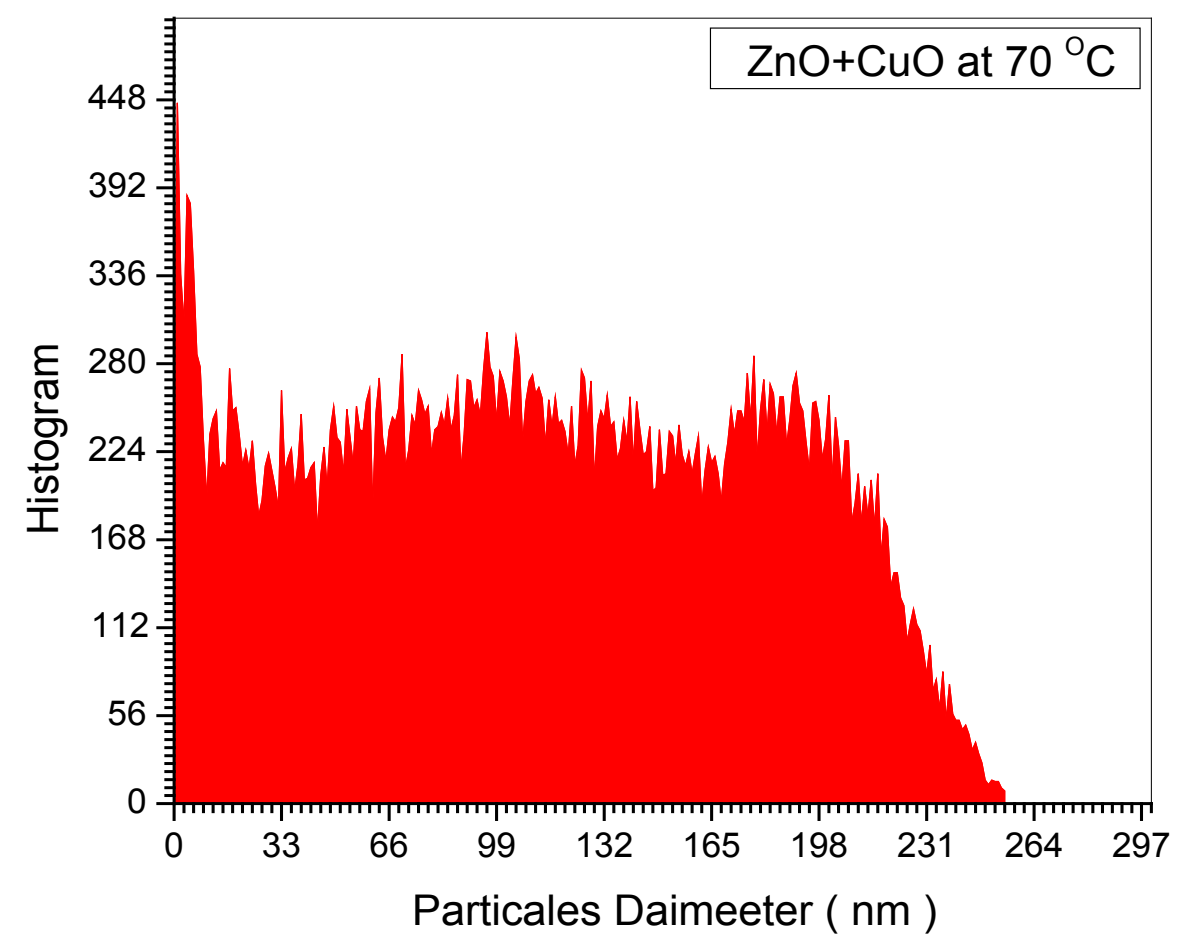

Figure 2. Particle diameter distribution of $\mathrm{ZnO}+\mathrm{CuO}$ sample films were annealed at $60^{\circ} \mathrm{C}$ temperatures.

Table 1. The I-V riding of $\mathrm{ZnO} / \mathrm{CuO} \mathrm{p}$-n junction for 8 samples by heated for different temperatures in the darkness (without exposed to direct light).

\begin{tabular}{ccccccccccc}
\hline $\begin{array}{c}\text { Voltage } \\
(\mathrm{V})\end{array}$ & $\begin{array}{c}\mathrm{I} \text { at } 60^{\circ} \mathrm{C} \\
(\mathrm{mA})\end{array}$ & $\begin{array}{c}\mathrm{I} \text { at } 70^{\circ} \mathrm{C} \\
(\mathrm{mA})\end{array}$ & $\begin{array}{c}\mathrm{I} \text { at } 80^{\circ} \mathrm{C} \\
(\mathrm{mA})\end{array}$ & $\begin{array}{c}\mathrm{I} \text { at } 90^{\circ} \mathrm{C} \\
(\mathrm{mA})\end{array}$ & $\begin{array}{r}\mathrm{I} \text { at } 100^{\circ} \mathrm{C} \\
(\mathrm{mA})\end{array}$ & $\begin{array}{c}\mathrm{I} \text { at } 110^{\circ} \mathrm{C} \\
(\mathrm{mA})\end{array}$ & $\begin{array}{c}\mathrm{I} \text { at } 120^{\circ} \mathrm{C} \\
(\mathrm{mA})\end{array}$ & $\begin{array}{c}\mathrm{I} \text { at } 130^{\circ} \mathrm{C} \\
(\mathrm{mA})\end{array}$ \\
\hline-10 & -0.01408 & -0.01498 & -0.01628 & -0.01809 & -0.02033 & -0.02236 & -0.02459 & -0.02705 \\
-8.11712 & -0.01359 & -0.01445 & -0.01571 & -0.01746 & -0.01962 & -0.02158 & -0.02373 & -0.02611 \\
-6.21522 & -0.01255 & -0.01336 & -0.01452 & -0.01613 & -0.01812 & -0.01994 & -0.02193 & -0.02412 \\
-4.31331 & -0.01042 & -0.01108 & -0.01205 & -0.01339 & -0.01504 & -0.01654 & -0.0182 & -0.02002 \\
-2.41141 & -0.00609 & -0.00648 & -0.00704 & -0.00782 & -0.00879 & -0.00967 & -0.01063 & -0.0117 \\
-0.50951 & 0.00236 & 0.00251 & 0.00273 & 0.00303 & 0.0034 & 0.00374 & 0.00412 & 0.00453 \\
1.39239 & 0.01766 & 0.01879 & 0.02042 & 0.02269 & 0.0255 & 0.02805 & 0.03085 & 0.03394 \\
3.29429 & 0.04202 & 0.04471 & 0.04859 & 0.05399 & 0.06067 & 0.06673 & 0.07341 & 0.08075 \\
5.1962 & 0.07379 & 0.0785 & 0.08533 & 0.09481 & 0.10653 & 0.11718 & 0.1289 & 0.14179 \\
7.0981 & 0.10598 & 0.11274 & 0.12254 & 0.13616 & 0.15299 & 0.16829 & 0.18512 & 0.20363 \\
\hline
\end{tabular}

$\mathrm{ZnO} / \mathrm{CuO} \mathrm{p}-\mathrm{n}$ junction increase when temperature increases for each samples by annealed different temperatures under particular solar radiation.

\section{Discussion}

In this work the $\mathrm{ZnO} / \mathrm{CuO}$ junction $\mathrm{V}$-I characteristics was studied in two cases firstly exposed to light directly secondly when it was no light (in darkness). 
When no light is exposed (in darkness), it was observed that upon increasing the temperature from 60 to 130 in steps of $10^{\circ} \mathrm{C}$, the current increases with temperature when the voltage is fixed. This may be attributed to the fact that the increase of temperature gives more electrons to gain thermal energy to move from the valance band to conduction band thus increases the current. It is also interesting to note that the current is nearly vanishes at a negative voltage equal to about -1.8 volt. This reflects the existence of reverse bias voltage and energy gap

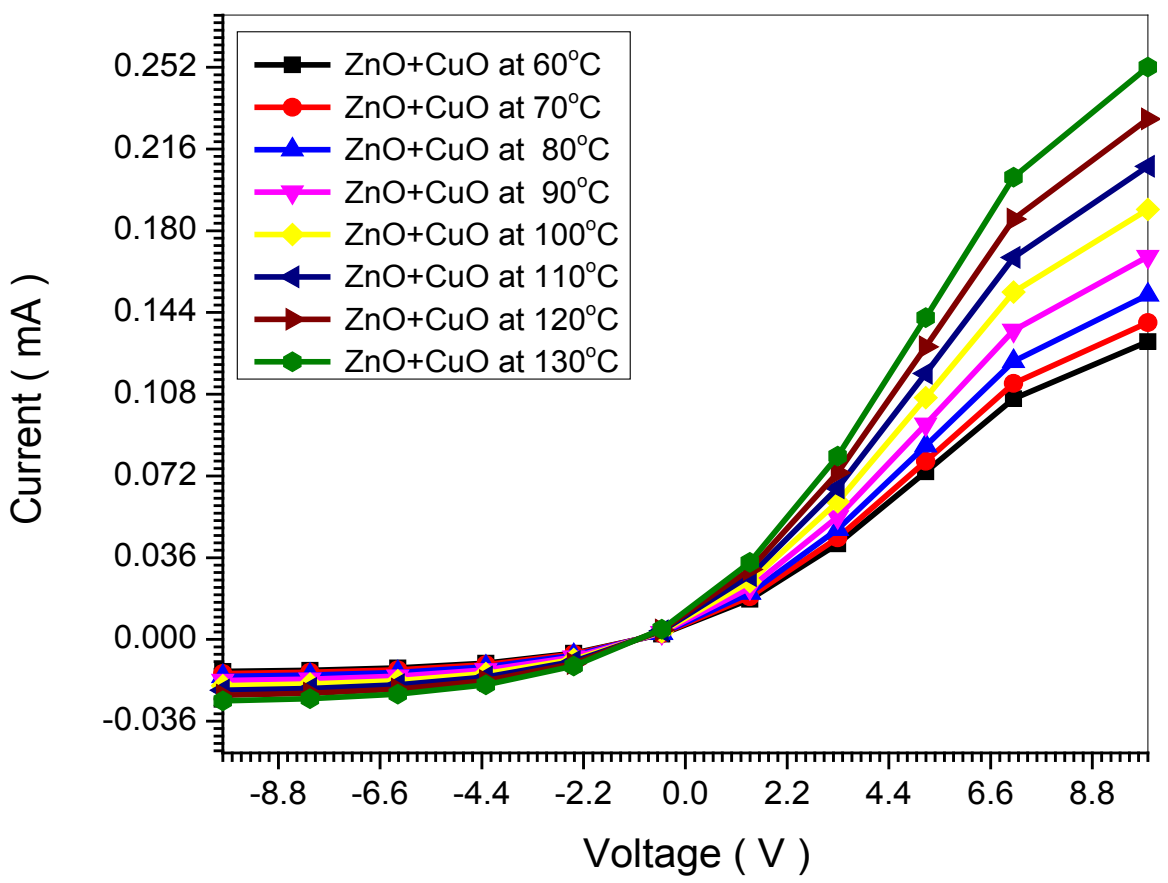

Figure 3. The I-V curves of $\mathrm{ZnO} / \mathrm{CuO}$ p-n junction for 8 samples by annealed different temperatures in the darkness.

Table 2. The I-V riding of $\mathrm{ZnO} / \mathrm{CuO}$ p-n junction for 8 samples by annealed different temperature.

\begin{tabular}{cccccccccc}
\hline $\begin{array}{c}\text { Voltage } \\
(\mathrm{V})\end{array}$ & $\begin{array}{c}\mathrm{I} \text { at } 60^{\circ} \mathrm{C} \\
(\mathrm{mA})\end{array}$ & $\begin{array}{c}\mathrm{I} \text { at } 70^{\circ} \mathrm{C} \\
(\mathrm{mA})\end{array}$ & $\begin{array}{c}\mathrm{I} \text { at } 80^{\circ} \mathrm{C} \\
(\mathrm{mA})\end{array}$ & $\begin{array}{c}\mathrm{I} \text { at } 90^{\circ} \mathrm{C} \\
(\mathrm{mA})\end{array}$ & $\begin{array}{c}\mathrm{I} \text { at } 100^{\circ} \mathrm{C} \\
(\mathrm{mA})\end{array}$ & $\begin{array}{c}\mathrm{I} \text { at } 110^{\circ} \mathrm{C} \\
(\mathrm{mA})\end{array}$ & $\begin{array}{c}\mathrm{I} \text { at } 120^{\circ} \mathrm{C} \\
(\mathrm{mA})\end{array}$ & $\begin{array}{c}\mathrm{I} \text { at } 130^{\circ} \mathrm{C} \\
(\mathrm{mA})\end{array}$ \\
\hline-15.000 & -1.00916 & -1.13389 & -1.21924 & -1.32526 & -1.45633 & -1.60196 & -1.60196 & -1.93837 \\
-12.027 & -0.8421 & -0.94618 & -1.01739 & -1.10586 & -1.21523 & -1.33676 & -1.33676 & -1.61748 \\
-9.0240 & -0.65522 & -0.7362 & -0.79162 & -0.86045 & -0.94555 & -1.04011 & -1.04011 & -1.25853 \\
-6.0210 & -0.44826 & -0.50366 & -0.54157 & -0.58866 & -0.64688 & -0.71157 & -0.71157 & -0.861 \\
-3.0180 & -0.21915 & -0.24624 & -0.26477 & -0.2878 & -0.31626 & -0.34789 & -0.34789 & -0.42095 \\
-0.0150 & 0.03433 & 0.03857 & 0.04148 & 0.04508 & 0.04954 & 0.0545 & 0.0545 & 0.06594 \\
2.9879 & 0.31463 & 0.35352 & 0.38013 & 0.41318 & 0.45405 & 0.49945 & 0.49945 & 0.60434 \\
5.9909 & 0.6244 & 0.70157 & 0.75438 & 0.81998 & 0.90107 & 0.99118 & 0.99118 & 1.19933 \\
8.9939 & 0.96649 & 1.08594 & 1.16768 & 1.26922 & 1.39474 & 1.53422 & 1.53422 & 1.8564 \\
11.997 & 1.34399 & 1.5101 & 1.62376 & 1.76496 & 1.93951 & 2.13347 & 2.13347 & 2.58149 \\
\hline
\end{tabular}




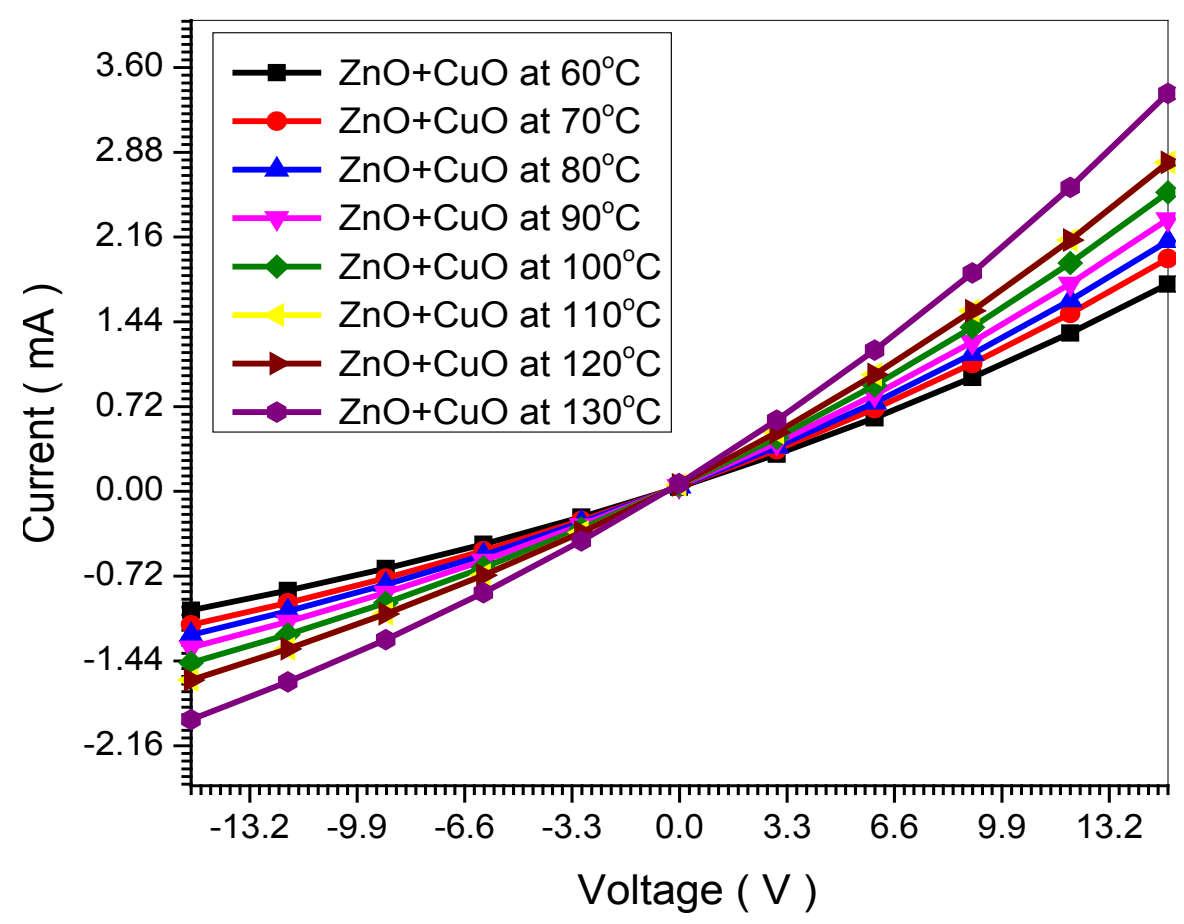

Figure 4. The $\mathrm{I}-\mathrm{V}$ curves of $\mathrm{ZnO} / \mathrm{CuO}$ p-n junction for 8 samples by annealed different temperatures under particular solar radiation.

of order $1.8 \mathrm{eV}$. The existence of negative reverse current is clearly conforms to relation:

$$
I=I_{0}\left(\mathrm{e}^{\beta V}-1\right)-I_{p}
$$

With $V$ and $I_{p}$ standing for operating voltage and photon generates current. For reverse bias the voltage is negative, thus the photon generates current dominance, thus $I=-I_{p}$ this current is assumed to be generated by invisible infra red photons in darkness. These infra red photons generated by human surrounding bodies and the building that exists near the $\mathrm{ZnO} / \mathrm{CuO}$ diodes. These photon generate currents are less than that generated in light as we will see later

The V-I characteristics in Figure 4 of $\mathrm{ZnO} / \mathrm{CuO}$ unction in light shows again increase in current when temperature increases. This result again confirm the fact that, temperature increase, increases thermal energy, which in turn increases the number of electrons that absorb this energy and transfer to the conduction band. This causes electric current to increase. It is also very interesting to note that the energy gap $E_{g}$, which correspond to zero current, increases with temperature, which agrees with theoretical relations, when

$$
n=n_{0} \mathrm{e}^{-\frac{E_{g}}{K T}} \text { and } E_{g}=K T \ln \frac{n_{0}}{n}
$$

where the energy gap $E_{g}$ is equal to the voltage that corresponding to zero current.

The effect of light can be observed clearly when comparing the values of reverse current at a certain voltage say (2.2 volt), where I in darks is $0.01 \mathrm{~mA}$, and 
light is about $0.7 \mathrm{~mA}$. This is relates to the fact that reverse current $I \sim I_{p}$. Thus in light current generated by visible photons is considerately large than that generated in dark by only free infra red photons.

\section{Conclusion}

The $\mathrm{ZnO} / \mathrm{CuO}$ diode energy gap and $\mathrm{V}$-I characteristics are sensitive to temperature as well as light. This sensitivity can be theoretically explained. Also it was found that for different temperature (60 to 130), the average Particle diameter varied from 1.5 micrometer to $92 \mathrm{~nm}$ which indicates that the particle size decreases with raising annealing temperature.

\section{References}

[1] Aksoy, S. and Caglar, Y. (2012) Effect of Ambient Temperature on Electrical Properties of Nanostructure $\mathrm{n}-\mathrm{ZnO} / \mathrm{p}-\mathrm{Si}$ Heterojunction Diode. Superlattices and Microstructures, 51, 613-625.

[2] Lupana, O., Pauportea, Th., Tiginyanu, I.M., Ursaki, V.V., Heinrich, H. and Chowc, L. (2011) Optical Properties of $\mathrm{ZnO}$ Nanowire Arrays Electrodeposited on n- and p-Type Si(111): Effects of Thermal Annealing. Materials Science and Engineering B, $176,1277-1284$.

[3] Brown, P.J. (2004) Experimental Attempts to Measure Non-Collinear Local Magnetisation. Journal of Physic and Chemistry of Solids, 65, 1977-1983.

[4] Cho, S.G., Nahm, T.-U. and Kim, E.K. (2014) Deep Level States and Negative Photoconductivity in n-ZnO/p-Si Hetero-Junction Diodes. Current Applied Physics, 14, 223-226.

[5] Lupan, O., Pauporte, T. and Viana, B. (2010) Low-Voltage UV-Electroluminescence from ZnO-Nanowire Array/p-GaN Light-Emitting Diodes. Advanced Materials, 22, 3298-3302.

[6] Pauporte, T. (2009) Design of Solution-Grown ZnO Nanostructures. In: Wang, Z.M., Ed., Lecture Notes on Nanoscale Science and Technology, Toward Functional Nanomaterials, Vol. 5, Springer Books, New York, 77-125.

https://doi.org/10.1007/978-0-387-77717-7_2

[7] Luo, L., Zhang, Y., Mao, S.S. and Lin, L. (2006) Fabrication and Characterization of $\mathrm{ZnO}$ Nanowires Based UV Photodiodes. Sensors and Actuators A: Physical, 127, 201.

[8] Lupan, O., Guerin, V.M., Tiginyanu, I.M., Ursaki, V.V., Chow, L., Heinrich, H. and Pauporte, T. (2010) Well-Aligned Arrays of Vertically Oriented ZnO Nanowires Electrodeposited on ITO-Coated Glass and Their Integration in Dye Sensitized Solar Cell. Journal of Photochemistry and Photobiology A: Chemistry, 211, 65-73.

[9] Pauporte, T., Lincot, D., Viana, B. and Pelle, F. (2006) Toward Laser Emission of Epitaxial Nanorods Arrays of $\mathrm{ZnO}$ Grown by Electrodeposition. Applied Physics Letters, 89, Article ID: 233112.

[10] Badre, C., Pauporte, T., Turmine, M. and Lincot, D. (2007) A ZnO Nanowire Array Film with Stable Highly Water-Repellent Properties. Nanotechnology, 18, Article ID: 365705 .

[11] Elamin, A.A., Ahmed, A.Z.A., Abd-Alla, M.D., Mohamed, A.S. and Ahamed, B.E. (2016) Self Magnitization Dependance of Iron Filings on Nano Particle Size. International Journal of Current Research, 8, 31116-31118. 